\title{
Quadruple Disruption of the Superior Shoulder Suspensory Complex (SSSC) and Outcome after One Year of Conservative Treatment: A Case Report
}

\author{
Felix Toft* and Fabrizio Moro
}

Upper Extremities, Schulthess Clinic, Lengghalde 2, 8008 Zurich, Switzerland

${ }^{*}$ Corresponding author: Felix Toft, Schulthess Clinic, Department of Orthopedics- Upper Extremities, Lengghalde 2, CH-8008 Zurich, Switzerland, Tel: +41 44385 7485; E-mail: felix.toft@kws.ch

Received date: March 16, 2016; Accepted date: April 01, 2016; Published date: April 05, 2016

Copyright: (C) 2016, Toft F, et al. This is an open-access article distributed under the terms of the Creative Commons Attribution License, which permits unrestricted use, distribution, and reproduction in any medium, provided the original author and source are credited.

\section{Introduction}

The Superior Shoulder Suspensory Complex (SSSC) comprises a bony and soft tissue ring including the clavicle, acromioclavicular (AC) joint, acromial process, glenoid fossa and process, coracoid process and coracoclavicular ligaments [1]. This complex is believed to have important biomechanical functions concerning shoulder stability and overall shoulder function, and connects the upper extremity via the clavicle with the axial skeleton [2]. Disruption of the SSSC at a single location due to a clavicle fracture, acromion fracture, or ACjoint dislocation with intact coracoclavicular (CC) ligaments, is a common injury often treated conservatively as the stability of the SSSC is still warranted, if no other indication for operative therapy exists. Double disruption of the SSSC is a rare injury thought to destabilize the construct, and therefore operative repair of one or both of the involved structures is recommended [3-8]. Triple and quadruple SSSC disruptions have been reported, although they are even rarer. They most often result from high energy trauma events, which are very often accompanied by associated injuries of the ribs, spine, nerves and head [9-18]. The more parts of the SSSC are injured, the greater the instability of the shoulder girdle. Thus, almost all of these injury types are treated surgically. We report on the radiological and functional outcome of a quadruple SSSC disruption, which was successfully treated in a conservative manner and followed up for one year posttrauma.

Keywords: Superior shoulder suspensory complex; Quadruple disruption; Conservative treatment; Functional outcome; Radiological outcome; Floating shoulder; Coracoid fracture; Acromion fracture

\section{Case Report}

A 74-year old male was referred to our clinic 16 days after falling on his right shoulder and elbow while dismounting his bicycle. During the 16-day post-trauma period, the patient suffered from persisting pain under load and functional impairment with restricted range of motion (ROM). An initial assessment on the day of the accident was performed at a hospital emergency department located near to the patient's residence. According to the report, the proximal humerus was tender on palpation and ROM was limited to $30^{\circ}$ active forward flexion/abduction. The patient was diagnosed with a shoulder contusion and suspicion of a rotator cuff tear as well as an open wound at the elbow; the latter was surgically cleaned and closed. Nine months prior to this current accident, the patient had undergone open reduction and internal fixation (ORIF) with a PHILOS $^{\circledR}$ long plate for a right proximal humeral shaft fracture without associated postoperative complaints.

On consultation at our clinic, a hematoma was still present at the scapular spine and right thoracic wall. Range of motion was limited to $80^{\circ} / 0^{\circ} / 30^{\circ}$ active forward flexion/extension, $80^{\circ}$ abduction, and $30 \%$ ( 0 / 3 external/internal rotation. The acromion and scapular spine as well as the coracoid process were tender on palpation. Initial radiographic assessment from the referring hospital showed several osseous fragments in the subacromial as well as intra-articular regions (Figure 1).

Computed tomography imaging (CT) of the affected shoulder revealed a small multifragmented posteroinferior fracture of the glenoid surface with an intra-articular step of 2 $\mathrm{mm}$, a fragment dislocation of $2.5 \mathrm{~mm}$, and a compression fracture of the anatomical scapular neck with caudal medialization of the glenoid fragment up to $10.4 \mathrm{~mm}$ (AO/OTA 14-C1.1) (Figure 2). The glenopolar angle (GPA) measured on the three-dimensional reconstruction was $21.4^{\circ}[19,20]$. Furthermore, there was an $8 \mathrm{~mm}$ dislocated fracture at the base of the coracoid process (Ogawa type I) [21], a $1 \mathrm{~cm}$ dislocated multifragmented fracture of the acromion at the lateral junction to the scapular spine (Kuhn type III) [22] with caudal displacement as well as some compromise of the subacromial space, and an AC-joint dislocation (Rockwood II) [23].

The subcoracoidal space measured $8.7 \mathrm{~mm}$. An assumed refracture of the proximal humerus was, in fact, an asymptomatic hypertrophic pseudarthrosis with only a marginal medial osseous bridge of around $2 \mathrm{~mm}$ and an otherwise persistent fracture gap of 4-8 $\mathrm{mm}$. Complementary to the $\mathrm{CT}$, we made an ultrasonogram to determine the status of the rotator cuff and tendon of the long head of the biceps; there was a partial lesion of the supraspinatus tendon with an otherwise intact rotator cuff and unremarkable biceps tendon.

We informed the patient about the extent of his injuries. He had limited but painless function of his right shoulder that was 
sufficient for undertaking his activities of daily living. The patient was also hesitant to undergo any surgical intervention almost three weeks after the bicycle accident. Consequently, both patient and physician agreed on conservative treatment involving assisted mobilization of the right shoulder under physiotherapeutic guidance with limited ROM $\left(70^{\circ}\right.$ abduction/ flexion without resistance/weightlifting) for three weeks, followed by free active ROM mobilization without resistance/ weightlifting for an additional six weeks.

At 6-weeks post-trauma, the patient remained pain free with $80^{\circ}$ active abduction/flexion, $20^{\circ}$ external rotation, and internal rotation at the $\mathrm{L} 3$ level. The patient could easily bring his hands together behind both his back and neck. No further dislocation was observed on the follow-up radiographs (Figure 3a), and the treatment protocol was maintained over the next three months.

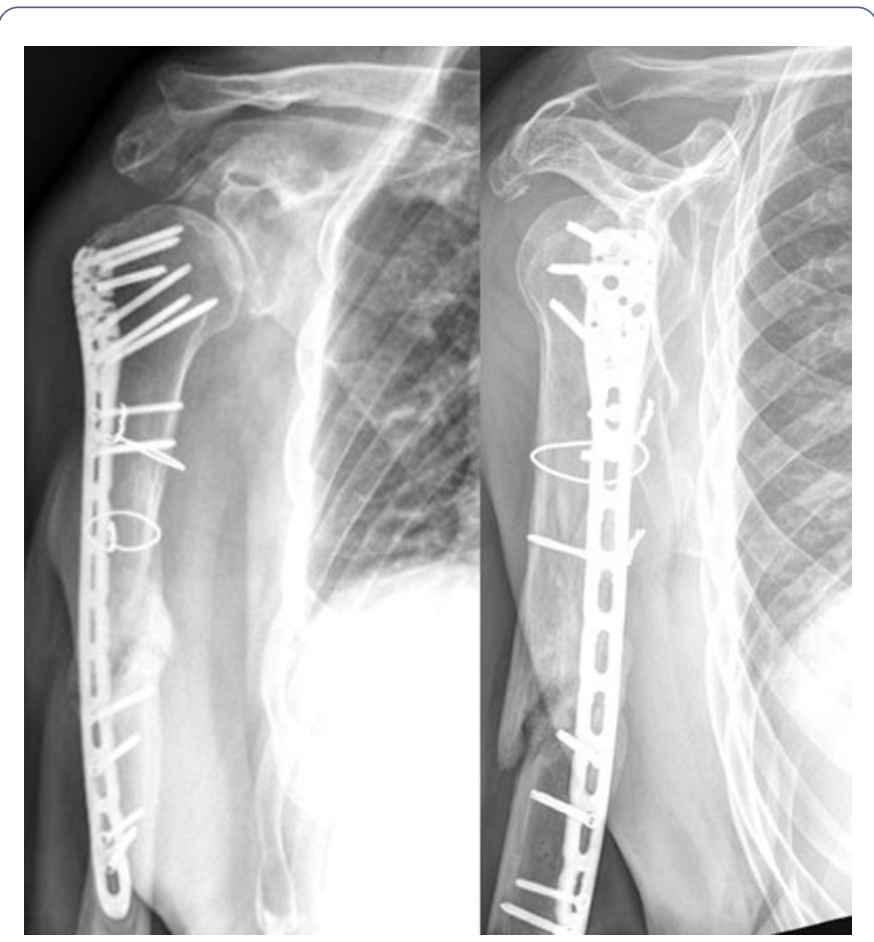

Figure 1: Radiograph of the 74-year old patient taken immediately after his bicycle accident at the hospital emergency unit showing PHILOS $^{\circledR}$ long plate fixation of a humerus fracture sustained nine months prior to the current trauma, and several osseous fragments in the subacromial as well as intra-articular regions as a result of the current trauma.

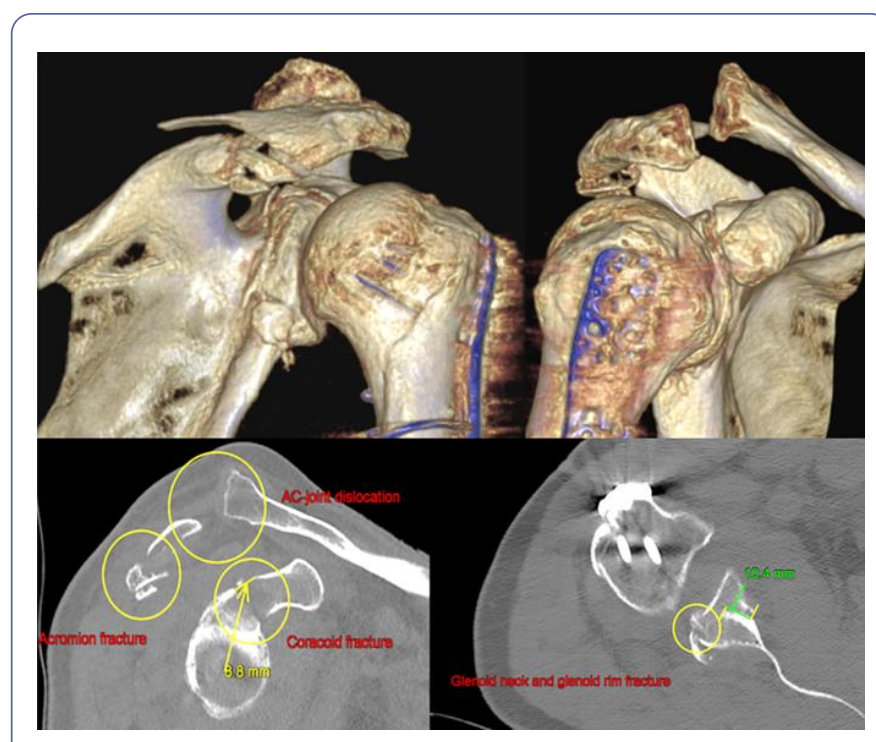

Figure 2: CT with 3D-reconstruction 16 days post-trauma revealing a quadruple disruption of the SSSC.

At a 12-week follow-up examination, active ROM increased to $100^{\circ}$ active abduction, $110^{\circ}$ active forward flexion and $30^{\circ}$ external rotation. Internal rotation remained at level $L 3$. The patient was still without pain. The 12-week radiograph showed no secondary dislocation of the fragments, but there were also no signs of fracture consolidation at the acromion or coracoid process (Figure $3 \mathrm{~b}$ ). Progressive callus formation was noted at the site of the humeral pseudarthrosis with concomitant fading of the former clearly visible fracture gap. Due to the achieved functional improvement and persistent lack of pain, we saw no indication for any surgical intervention.

By the 6-month post-trauma period, the patient achieved active ROM of $100^{\circ}$ abduction, $120^{\circ}$ forward flexion, $80^{\circ}$ external rotation, and Th12 level internal rotation. Passive glenohumeral abduction with the scapula fixed was $85^{\circ}$ without signs of symptomatic subacromial impingement. Resisted abduction measured with a spring scale was $7 \mathrm{~kg}$ on the affected right side and $11 \mathrm{~kg}$ on the contralateral shoulder. Radiographic evidence of secondary dislocation was still lacking and there was callus formation at the coracoid base and scapular neck, although still no genuine signs of callus formation at the acromion (Figure $3 \mathrm{c}$ ). An increasing callus bridge at the former pseudarthrosis site of the humerus associated with the disappearance of the formally visible fracture line was noted.

The patient was pain free (visual analogue scales (VAS) score of 0 ) and made further gains in shoulder function by the final 1 -year evaluation. Active forward flexion and abduction was $140^{\circ}$ with no change in external rotation and a slight decline to L3 internal rotation. Passive glenohumeral abduction remained at $85^{\circ}$. Internal and external rotation in $90^{\circ}$ abduction was $0^{\circ} / 0^{\circ} / 90^{\circ}$ (Figure 4). There was no tenderness on palpation or crepitus either along the scapular spine, acromion or at the coracoid process. Abduction strength was 8 and $12 \mathrm{~kg}$ on the affected right and contralateral sides, respectively. The 1-year Constant score (CS) was 84 points. For the patient self- 
completion Disability of the Arm, Shoulder and Hand (DASH) and American Shoulder and Elbow Surgeons (ASES) questionnaires, the 1-year scores were 0 and 100 , respectively. Increasing fracture consolidation at the coracoid base and scapula neck as well as progressive fracture healing at the dorsal acromion was observed on the 1-year radiographs (Figure $3 d$ ). Yet true union of all fractures could not be determined without additional 1-year CT. Because the patient continued to be completely unrestrained with his right shoulder, particularly in his daily activities of biking and hiking as well as his pain free status even under load, further CT examinations were unnecessary and declined by both physician and patient.

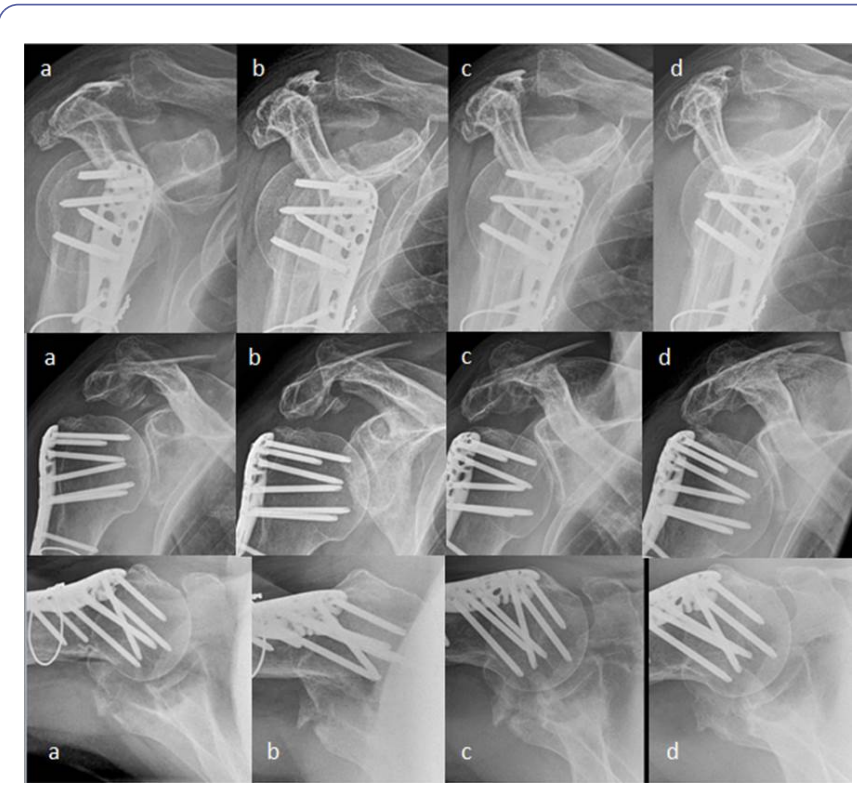

Figure 3: From top to bottom: Morrison outlet view, anterior-posterior in external rotation and axial radiographs. From left to right: radiographs at six weeks (a), 12 weeks (b), six months (c) and 12 months (d) post-trauma.

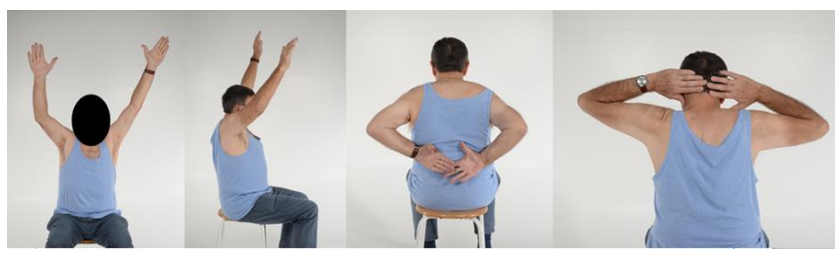

Figure 4: Functional outcome 12 months post-trauma.

\section{Discussion}

This case report describes the radiological and functional outcome after conservative treatment of a quadruple disruption of the SSSC, with astonishingly satisfactory results for our patient. Higher grade SSSC disruptions reported in the literature have been treated surgically with predominantly good to excellent outcomes at final follow up (6 months to 5 years post-surgery) [24-34]. Hence, the recommendation of surgical fixation for such unstable fracture patterns is established, especially if fracture dislocation is present. Good clinical results after conservative therapy of double disruptions/floating shoulders with only minimally displaced fractures exist [35-40], yet more studies report the inferior outcome of conservatively versus surgically treated displaced fractures [41-44]. There is a lack of data concerning outcome after conservative treatment for triple or quadruple SSSC disruptions.

There is on-going debate about the treatment strategies for higher grade disruptions of the SSSC as well as isolated coracoid or scapula neck fractures. Recommendations are predominantly based on expert opinion, case reports and small case series that lack the level of evidence to advocate clear surgical indications or the superiority of either surgical or nonsurgical treatment for minimally displaced fractures $[12,44]$. Decision making depends greatly on the accuracy of the treating physician to measure fracture displacement and estimate instability.

Ogawa et al. recommended ORIF of displaced ( $>5 \mathrm{~mm}$ ) type I coracoid fractures, as they most often occur with concomitant lesions of the SSSC and are thus considered unstable. Isolated coracoid fractures, on the other hand, are mostly non-displaced $(<5 \mathrm{~mm})$ and can be treated conservatively due to intact ligamentous stability [29,30]. Hill et al. has more recently described a higher threshold for surgical fixation with a fracture displacement of greater than or equal to $1 \mathrm{~cm}$ [18]. Our patient's fracture was considerably displaced $(8 \mathrm{~mm})$, but without significant rotational malalignment (probably due to intact CC and AC ligaments) or compromise of the subcoracoidal space.

For acromial process fractures, Kuhn et al. proposed surgery for type III fractures with compromise of the subacromial space [21]. The acromial fracture presented in our report represents a type III fracture due to the obvious caudal displacement.

Fractures of the glenoid neck involve either the anatomical or surgical neck, depending on the fracture line exiting medial or lateral to the coracoid base. Anatomical neck fractures are rare with only eight cases reported in the English literature, generally considered unstable, and surgical fixation is recommended especially if concomitant SSSC injuries are present $[2,4,5,11]$. Bartoníček et al. presented 17 scapular neck fractures, of which four were isolated anatomical neck fractures along with eight surgical neck and five trans-spinous fractures [5]. Fracture displacement of greater than or equal to $1 \mathrm{~cm}$ and/or a GPA falling outside the range of $26^{\circ}$ to $55^{\circ}$ were indications for surgery. Of the four anatomical neck fractures, three were treated surgically and one non-displaced fracture with a GPA of $38^{\circ}$ was treated conservatively. After 1 year, the conservatively treated anatomical neck fracture of a 25-year old male healed and the patient reached a CS score of 100 points. Two of the three surgically fixed fractures had 1-year follow up data, with the third followed up to 11 years postsurgery; final Constant scores for these three patients aged 51, 36 and 51 years was 57, 96 and 98 points, respectively. Our patient had a markedly decreased GPA due to the caudal impaction of the glenoid fragment without translational, 
angular or rotational displacement. The posteroinferior glenoid rim fracture was neither markedly displaced nor large enough to cause instability or a relevant intra-articular gap, therefore, our decision for nonoperative treatment was undisputed [4].

There were clear indications for surgical fixation of almost all fracture components, especially since the specific combination of injuries represented a quadruple disruption of the SSSC $[6,11,13,20,26,33,36,42]$. After our thorough diagnosis of an injury sustained two weeks earlier and accompanied by a successive decrease in pain as well as sufficient shoulder function to cope with the patient's everyday demands, we had the opportunity to follow the natural history of such a rare fracture pattern in an elderly patient. While radiological signs of fracture healing were ambiguous until the 6-month follow up, shoulder flexion/ abduction had improved; this outcome is similar to that expected after inverse shoulder arthroplasty in proximal humeral fractures or in the case of cuff tear arthropathy $[27,37]$. The patient had excellent 1-year post-treatment shoulder function for his age group and fracture pattern type. Shoulder outcome scores were optimal and the patient was unrestrained in his daily housework, gardening and sports activities. The degree to which the pseudarthrosis of the humerus or the locking plate contributed to the fracture pattern or influenced the natural history of the SSSC injury under conservative treatment cannot be determined. These factors should nevertheless be considered in any further interpretation of this unique case.

The drawback of this case remains that it is the first and only report highlighting such a treatment choice. If we had seen the patient earlier, we believe that surgical fixation would have been our treatment of choice based on biomechanical considerations and hereby expected poor outcome following conservative treatment, as well as lacking reports of successful conservative management. Therefore, we consider this case an important source of information for future treatment strategies potentially favoring conservative management in comparable cases. Another limitation is the short follow-up time without mid- or long-term results, which could reveal future impingement problems, progressive osteoarthritis or gradually deteriotating shoulder function due to rotator cuff insufficiency caused by glenoid fragment medialization and altered biomechanics (rotator cuff/deltoid preload, reduced critical shoulder angle) [16,25].

\section{Conclusion}

Although multiple disruptions of the SSSC are rare, they may become more frequent in an ever-increasing aging, yet active population. Our case report highlights the relevance of conservative treatment as an option for these "non-highdemand" patients who may achieve acceptable functional outcome, despite their unstable injuries. Elderly patients are more likely to have relevant comorbidities that affect their perioperative risk of complications. Conservative management would therefore present an ideal treatment choice, if a favourable outcome was to be confirmed by further studies.

\section{References:}

1. Ada JR, Miller ME (1991) Scapular fractures. Analysis of 113 cases. Clin Orthop Relat Res 269: 174-180.

2. Anavian J, Gauger EM, Schroder LK, Wijdicks CA, Cole PA (2012) Surgical and functional outcomes after operative management of complex and displaced intra-articular glenoid fractures. J Bone Joint Surg Am 94: 645-653.

3. Anavian J, Conflitti JM, Khanna G, Guthrie ST, Cole PA (2011) a reliable radiographic measurement technique for extra-articular scapular fractures. Clin Orthop Relat Res 469: 3371-3378.

4. Bahk MS, Kuhn JE, Galatz LM, Connor PM, Williams GR Jr. (2009) Acromioclavicular and sternoclavicular injuries and clavicular, glenoid, and scapular fractures. J Bone Joint Surg Am 91: 2492-2510.

5. Bartoníček J, Tuček M, Frič V, Obruba P (2014) Fractures of the scapular neck: diagnosis, classifications and treatment. Int Orthop 38: 2163-2173.

6. Cole PA, Gauger EM, Herrera DA, Anavian J, Tarkin IS (2012) Radiographic follow-up of 84 operatively treated scapula neck and body fractures. Injury 43: 327-333.

7. de Hartog B, de van Boom LGH, van Raaij JJAM (2009) The floating shoulder. Nederlands Tijdschrift voor Traumatologie 17: 167-170.

8. Edwards SG, Whittle AP, Wood GW (2000) Nonoperative treatment of ipsilateral fractures of the scapula and clavicle. J Bone Joint Surg Am 82: 774-780.

9. Egol KA, Connor PM, Karunakar MA, Sims SH, Bosse MJ, et al. (2001) The floating shoulder: clinical and functional results. J Bone Joint Surg Am 83: 1188-1194.

10. Friederichs J, Morgenstern M, Bühren V (2014) Scapula fractures in complex shoulder injuries and floating shoulders: a classification based on displacement and instability. J Trauma Manag Outcomes 8: 16.

11. Gilde AK, Hoffmann MF, Sietsema DL, Jones CB (2015) Functional outcomes of operative fixation of clavicle fractures in patients with floating shoulder girdle injuries. J Orthop Traumatol 16: 221-227.

12. Goss TP, Owens BD (2009) Fractures of the scapula. In: Rockwood CA, Matsen FA, eds. The Shoulder, 4th Edition. Elsevier Health Sciences 333-380.

13. Goss TP (1996) The scapula: coracoid, acromial, and avulsion fractures. Am J Orthop (Belle Mead NJ) 25: 106-115.

14. Goss TP (1995) Scapular fractures and dislocations: diagnosis and treatment. J Am Acad Orthop Surg 3: 22-33.

15. Goss TP (1993) Double disruptions of the superior shoulder suspensory complex. J Orthop Trauma 7: 99-106.

16. Hardegger FH, Simpson LA, Weber BG (1984) the operative treatment of scapular fractures. J Bone Joint Surg Br 66: 725731.

17. Hill BW, Anavian J, Jacobson AR, Cole PA (2014) surgical management of isolated acromion fractures: technical tricks and clinical experience. J Orthop Trauma 28: e107-113.

18. Hill BW, Anavian J, Jacobson AR, Cole PA (2014) surgical management of coracoid fractures: technical tricks and clinical experience. J Orthop Trauma 28: e114-122. 
19. Jung CY, Eun IS, Kim JW, Ko YC, Kim YJ, et al. (2011) Treatment of triple fracture of the superior shoulder suspensory complex. J Korean Orthop Assoc 46: 68-72.

20. Kim SH, Chung SW, Kim SH, Shin SH, Lee YH (2012) Triple disruption of the superior shoulder suspensory complex. Int J Shoulder Surg 6: 67-70.

21. Kuhn JE, Blasier RB, Carpenter JE (1994) Fractures of the acromion process: a proposed classification system. J Orthop Trauma 8: 6-13.

22. Lantry JM, Roberts CS, Giannoudis PV (2008) Operative treatment of scapular fractures: a systematic review. Injury 39: 271-283.

23. Lecoq C, Marck G, Curvale G, Groulier P (2001) Triple fracture of the superior shoulder suspensory complex. Acta Orthop Belg 67: 68-72.

24. Liu AJ, Chen PJ, Shen PW (2013) Triple injury to the superior shoulder suspensory complex. Formosan Journal of Musculoskeletal Disorders 4: 81-83.

25. Moor BK, Bouaicha S, Rothenfluh DA, Sukthankar A, Gerber C (2013) is there an association between the individual anatomy of the scapula and the development of rotator cuff tears or osteoarthritis of the glenohumeral joint? A radiological study of the critical shoulder angle. Bone Joint J 95: 935-941.

26. Mulawka B, Jacobson AR, Schroder LK, Cole PA (2015) Triple and quadruple disruptions of the superior shoulder suspensory complex. J Orthop Trauma 29: 264-270.

27. Nolan BM, Ankerson E, Wiater JM (2011) Reverse total shoulder arthroplasty improves function in cuff tear arthropathy. Clin Orthop Relat Res 469: 2476-2482

28. Nordqvist A, Petersson C (1992) Fracture of the body, neck, or spine of the scapula: a long-term follow-up study. Clin Orthop Relat Res 283: 139-144.

29. Ogawa K, Matsumura N, Ikegami H (2012) Coracoid fractures: therapeutic strategy and surgical outcomes. J Trauma Acute Care Surg 72: E20-E26.

30. Ogawa K, Toyama Y, Ishige S, Matsui K (1990) Fracture of the coracoid process: its classification and pathomechanism. J Jpn Orthop Assoc 64: 909-919.

31. Oh W, Jeon IH, Kyung S, Park C, Kim T, et al. (2002) The treatment of double disruption of the superior shoulder suspensory complex. Int Orthop 26: 145-149.
32. Oshima M, Nakagawa $Y$, Mondori T (2003) Complex injury patterns of the shoulder girdle-three or four-site injury. Shoulder Joint 27: 555-559.

33. Owens BD, Goss TP (2006) the floating shoulder. J Bone Joint Surg $\mathrm{Br}$ 88: 1419-1424.

34. Ramos L, Mencia R, Alonso A, Ferrandez L (1997) Conservative treatment of ipsilateral fractures of the scapula and clavicle. J Trauma 42: 239-242.

35. Rockwood CA, Williams G, Young D (1998) Disorders of the acromioclavicular joint. In: Rockwood CA Jr, Matsen FA II, eds. The Shoulder, Volume 1 (2nd ed). Philadelphia: WB Saunders 483-553.

36. Romero J, Schai P, Imhoff AB (2001) Scapular neck fracture--the influence of permanent malalignment of the glenoid neck on clinical outcome. Arch Orthop Trauma Surg 121: 313-316.

37. Ross M, Hope B, Stokes A, Peters SE, McLeod I, et al. (2015) Reverse shoulder arthroplasty for the treatment of three-part and four-part proximal humeral fractures in the elderly. J Shoulder Elbow Surg 24: 215-222.

38. Sung CM, Park HB (2012) Triple disruption of the Superior Shoulder Suspensory Complex: case report at 5-year-follow up. Clin Should Elbow 15: 143-147.

39. Mariño IT, Rodríguez IM, Villadeamigo JM (2013) Triple fracture of the shoulder suspensory complex. Revista Española de Cirugía Ortopédica y Traumatología (English Edition) 57: 371-374.

40. Tuček M, Naňka O, Malík J, Bartoníček J (2014) the scapular glenopolar angle: standard values and side differences. Skeletal Radiol 43: 1583-1587.

41. van Noort A, Te Slaa RL, Marti RK, van der Werken C (2001) the floating shoulder. A multicentre study. J Bone Joint Surg Br 83: 795-798.

42. Voleti PB, Namdari S, Mehta S (2012) Fractures of the scapula. Adv Orthop 2012: 903850.

43. Yin SQ, Pan J, Guo XS, Wu SK (2012) Treatment strategy of double disruption of the superior shoulder suspensor complex (SSSC). Zhongguo Gu Shang 25: 170-172.

44. Zlowodzki M, Bhandari M, Zelle BA, Kregor PJ, Cole PA (2006) Treatment of scapula fractures: systematic review of 520 fractures in 22 case series. J Orthop Trauma 20: 230-233. 